\title{
PREDOMINANCE OF BLOW FLIES (DIPTERA: CALLIPHORIDAE) AMONG INSECTS VISITING FLOWERS OF BUCHANANIA LANZAN (SAPINDALES: ANACARDIACEAE)
}

\author{
MOOPHAYAK, K. ${ }^{*}$ - MeEINKUIRT, W. \\ Mahidol University, Nakhonsawan Campus, Nakhon Sawan 60130, Thailand \\ *Corresponding author \\ e-mail:khun_khithop@hotmail.com \\ (Received 25 ${ }^{\text {th }}$ Apr 2017; accepted $21^{\text {st }}$ Jul 2017)
}

\begin{abstract}
This study highlighted blow flies as new possible pollinators of Buchanania lanzan (Sapindales: Anacardiaceae) flowers. Two sets of 2-day sampling were done by using a sweep net on the flowers of B. lanzan in a deciduous forested area of Mahidol University, Nakhonsawan Campus, Nakhon Sawan Province, Thailand during 27-28 December 2013 and 13-14 December 2014. The number of flies (Diptera) collected was larger than the combined number of bees (Hymenoptera) and beetles (Coleoptera) by a factor of 9.4. Blow flies (Diptera: Calliphoridae) were the most abundant insects caught (34.8\% of total), and included the medically-important Chrysomya megacephala. Stomorhina discolor predominated (23.6\% of total), followed by C. megacephala, C. rufifacies, C. nigripes and Rhyncomya flavibasis. Female flies predominated over males and were mostly collected in the morning. Many pollen grains were attached to the bodies of the flies, especially on the legs, thorax, and/or abdomen, indicating the likely importance of blow flies as pollinators of the blossoms of $B$. lanzan. These new findings could be useful for furthering conservation management and economic production of $B$. lanzan, and also for the use of $B$. lanzan flowers or the chemicals which they extrude as bait for controlling medically-important fly populations.
\end{abstract}

Keywords: Almondette, insect diversity, pollinator, Stomorhina discolor, wasp-mimicking flies

\section{Introduction}

Buchanania lanzan (Spreng) (common name Almondette, family Anacardiaceae) is found growing naturally as a wild plant in subtropical and tropical deciduous forests in many countries, including Thailand (Wongpakam et al., 2007; Sereesongsaeng and Khumchompoo, 2009), Myanmar, Malaysia, India (Martin et al., 1988), Australia and the Pacific islands (Chauhan et al., 2012). The tree is moderate-sized with alternate and simple leaves. Many parts of $B$. lanzan have socio-economic or medicinal importance, particularly in India. Its kernel is a commercially edible nut and is regarded as substitute for almonds in desert habitats (Rosengarten, 1984). Prasad and Bhatnagar (1993) reported that more than one thousand tons of kernels were harvested yearly from native forests of Mahdya Pradesh and Chhattisgarh in India (Duke, 2000). The other parts of this plant are of phytomedical and pharmaceutical importance and are used in Indian folk medicine to treat wounds, skin diseases, and diarrhoea (Patsnaik et al., 2011; Kumar et al., 2012). The bark may also be beneficial for application under conditions of immune stimulation and/or bacterial infection (Sekhar et al., 2015). Unfortunately, no commercial farming of $B$. lanzan has been carried out. Thus, ecological management may be needed to balance the demands of medicinal utility and tree conservation (Chauhan et al., 2012).

During reproduction, the flowers are formed in a panicle. As in the mango, Mangifera indica, both staminate flowers and hermaphrodite flowers are present in each panicle, but pollination is achieved by neither self-propagation nor wind pollination. 
Insect pollination is therefore presumed to play a significant role in propagation (Huda et al., 2015).

Blow flies (Diptera: Calliphoridae) are considered to be of medical and veterinary concern, and to have negative impacts on public health worldwide (Greenberg, 1973). From an ecological and agricultural standpoint, however, blow flies are potentially important pollinators of flowers including mango, from which they gather pollen or nectar on their legs and body surfaces during feeding (Anderson et al., 1982; Hu et al., 1995).

At Mahidol University Nakhonsawan Campus, when B. lanzan trees were blooming during December 2012, casual visitors to the vicinity of the trees assumed that the buzzing sound was from bees or wasps. After conducting preliminary observations, however, first author found that almost all of insects at the tree were flies such as Chrysomya megacephala, Chrysomya rufifacies and Stomorhina discolor. The objective of this study was therefore to determine the relationship between blow flies and flowers of B. lanzan.

\section{Materials and Methods}

\section{Study site}

Insect sampling was conducted at a $B$. lanzan tree on the Mahidol University Nakhonsawan Campus, Nakhon Sawan Province, north-central Thailand for a two-day period during two successive dry seasons (27-28 December 2013 and 13-14 December 2014), coinciding with the flowering period of B. lanzan. The B. lanzan tree sampled was located outside the administrative offices of the university $\left(15.57912^{\circ} \mathrm{N}\right.$, $100.43717^{\circ} \mathrm{E}$ ) (Figure 1A).

Shorea obtusa (Wall. ex Blume.) and Shorea siamensis (Miq.) have been found commonly near the study site. They are common trees in a disturbed deciduous dipterocarp forest. In a radius of $20 \mathrm{~m}$, an additional 10 trees of Azadirachta indica (A. Juss.) (3), Diospyros rhodocalyx (Kurz.) (1), Maerua siamensis (Kurz) Pax. (3), Pterocarpus indicus (Willd.) (2) and S. obtusa (1) were found.

Weather data collected at Nakhonsawan Meteorological Station $\left(15.67213^{\circ} \mathrm{N}\right.$, $\left.100.12962^{\circ} \mathrm{E}\right), \sim 10 \mathrm{~km}$ distance from the study site, showed that daytime maximum temperatures reached $33.8{ }^{\circ} \mathrm{C}$ and $35.5{ }^{\circ} \mathrm{C}$ during December 2013 and 2014, respectively (www.met-sawan.tmd.go.th). Rainfall was c. $2.4 \mathrm{~mm}$ during December 2014, while; no rain fell during December 2013.

\section{Insect sampling on B. lanzan flowers}

A sweep net was used to catch all insects swarming over the flowers of B. lanzan during $3 \mathrm{~h}$ in the morning (0900-1200 h) and $3 \mathrm{~h}$ in the afternoon (1300-1600 h), in order to examine the pattern of insect visitation. All insects collected were anesthetized in an ethyl acetate killing jar. The insects were sorted to family using the taxonomic key of Triplehorn and Johnson (2005), and then identified to genus and species (where possible) under a stereo microscope (Olympus, Japan). Blow flies and muscid flies were identified using the taxonomic keys of Kurahashi and Bunchu (2011) and Tumrasvin and Shinonaga (1977), respectively. Unknown species were grouped as morpho-species. 
All insects were pinned and observed for attachment of pollen under the stereo microscope. Finally, all insects were deposited in preservation boxes at Mahidol University Nakhonsawan Campus.
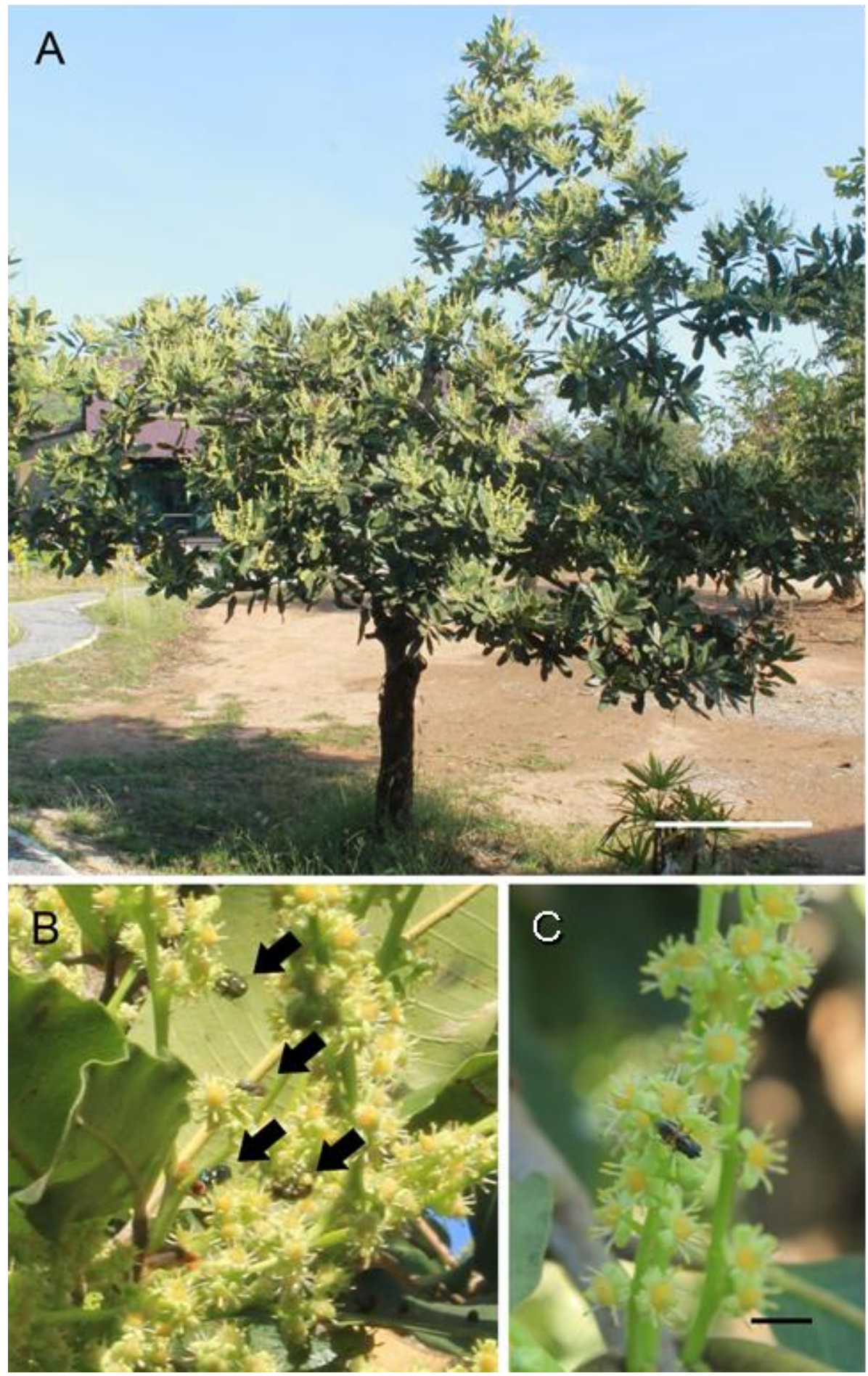

Figure 1. The sampled Buchanania lanzan tree, located near the administrative offices of Mahidol University Nakhonsawan Campus, Nakhonsawan Province, Thailand; (A) the tree with flowers (bar = $1 \mathrm{~m}) ;(B)$ various blow fly species visiting the blossom (black arrow heads); and (C) Stomorhina discolor, the predominant species visiting blossoms $($ bar $=1 \mathrm{~cm})$ 


\section{Data analyses}

The numbers of individuals of each insect species collected from the B. lanzan tree were counted.

Statistical analysis was performed using SPSS 17.0 for Windows. ANOVA was used to determine the difference among numbers of flies (males vs. females) collected during morning (0900-1200 h) and afternoon (1300-1600 h) (p < 0.05).

\section{Results}

\section{Diversity of insects on B. lanzan flowers}

A total of 843 insects were collected during investigations (Table 1). The numbers of insects collected between years were quite similar, with 404 insects in 2013 and 439 insects in 2014. Insects were sorted into 3 orders. Flies (Diptera) ranked as by far the most abundant insects, while the combined number of bees (Hymenoptera: Apis mellifera) and beetles (Coleoptera) contributed only $3.7 \%$ of the total.

Table 1. Classification and total number (\%) of insect species visiting flower of Buchanania lanzan at Mahidol University Nakhonsawan Campus, during 2-day sampling of 27-28 December 2013 and 13-14 December 2014

\begin{tabular}{|c|c|c|c|}
\hline Order & Family & Species & No. $(\%)$ \\
\hline \multirow[t]{17}{*}{ Diptera } & Calliphoridae & Stomorhina discolor (Fabricius, 1794) & $199(23.6)$ \\
\hline & & Chrysomya megacephala (Fabricius, 1794) & $57(6.8)$ \\
\hline & & Chrysomya rufifacies (Macquart, 1843) & $30(3.6)$ \\
\hline & & Ceynolomyia nigripes (Aubertin, 1923) & $5(0.6)$ \\
\hline & & Rhyncomya flavibasis (Senior-White, 1922) & $2(0.2)$ \\
\hline & Syrphidae & Undetermined & $156(18.5)$ \\
\hline & Stratiomyidae & Hedriodiscus sp. & $116(13.8)$ \\
\hline & Drosophilidae & Drosophila melanogaster Meigen, 1830 & $96(11.4)$ \\
\hline & Muscidae & Graphomya rufitibia Stein, 1918 & $66(7.8)$ \\
\hline & & Musca sorbens Wiedeman, 1830 & $19(2.2)$ \\
\hline & Phoridae & Megaselia scalaris Loew, 1866 & $12(1.4)$ \\
\hline & Sarcophagidae & Boetcherisca peregrina Robineuau-Desvoidy, 1930 & $4(0.5)$ \\
\hline & & Parasarcophaga dux Thomson, 2867 & $3(0.4)$ \\
\hline & & Sarcophaga spp. Meigen, 1826 & $2(0.2)$ \\
\hline & Tachinidae & Tachinid fly & $7(0.8)$ \\
\hline & Tabanidae & Tabanus sp. Linnaeus, 1758 & $3(0.4)$ \\
\hline & Undetermined & Undetermined Diptera & $35(4.2)$ \\
\hline Hymenoptera & Apidae & Apis mellifera Linnaeus, 1758 & $24(2.8)$ \\
\hline Coleoptera & Undetermined & Undetermined & $7(0.8)$ \\
\hline Total & & & 843 (100) \\
\hline
\end{tabular}


Ten families of flies were found on B. lanzan flowers (Table 1). Of these, blow flies (Calliphoridae) were the most abundant $(34.8 \%$ of total) and species-rich $(\mathrm{R}=5$ species). These comprised Stomorhina discolor (Fig. 1B-C), Chrysomya megacephala (Fig. 1B), Chrysomya rufifacies, Chrysomya nigripes, and Rhyncomya flavibasis.

Syrphid flies (Syrphidae) were the second most abundant $(18.5 \%$ of total; $R=4)$ and comprised 4 morpho-species. Hedriodiscus sp. (Stratiomyidae), Drosophila melanogaster (Drosophilidae), and Graphomya rufitibia and Musca sorbens (Muscidae) all contributed high numbers in our samples. Otherwise, Megaselia scalaris (Phoridae), Boetcherisca peregrina, Parasarcophaga dux, Sarcophaga sp. (Sarcophagidae), and other undetermined Diptera were much less abundant. Blood-sucking flies (Tabanidae: Tabanus sp.) contributed just 3 individuals (Table 1).

\section{Visitation of insects on B. lanzan flowers}

The number of insects visiting the flowers of B. lanzan was higher during the morning (0900-1200 h) than the afternoon (1300-1500 h) (Fig. 2). The difference in the numbers visiting between morning and afternoon periods was significant in the blow flies $S$. discolor and C. megacephala ( $\mathrm{p}=0.002$ and 0.023 , respectively). Significant differences were also found in Hedriodiscus sp., D. melanogaster, G. rufitibia, and syrphid flies $(\mathrm{p}<0.05)$. No significant difference was found in the diurnal visitation pattern of A. mellifera or beetles, while $R$. flavibasis and Tabanus sp. were only found during the morning period.

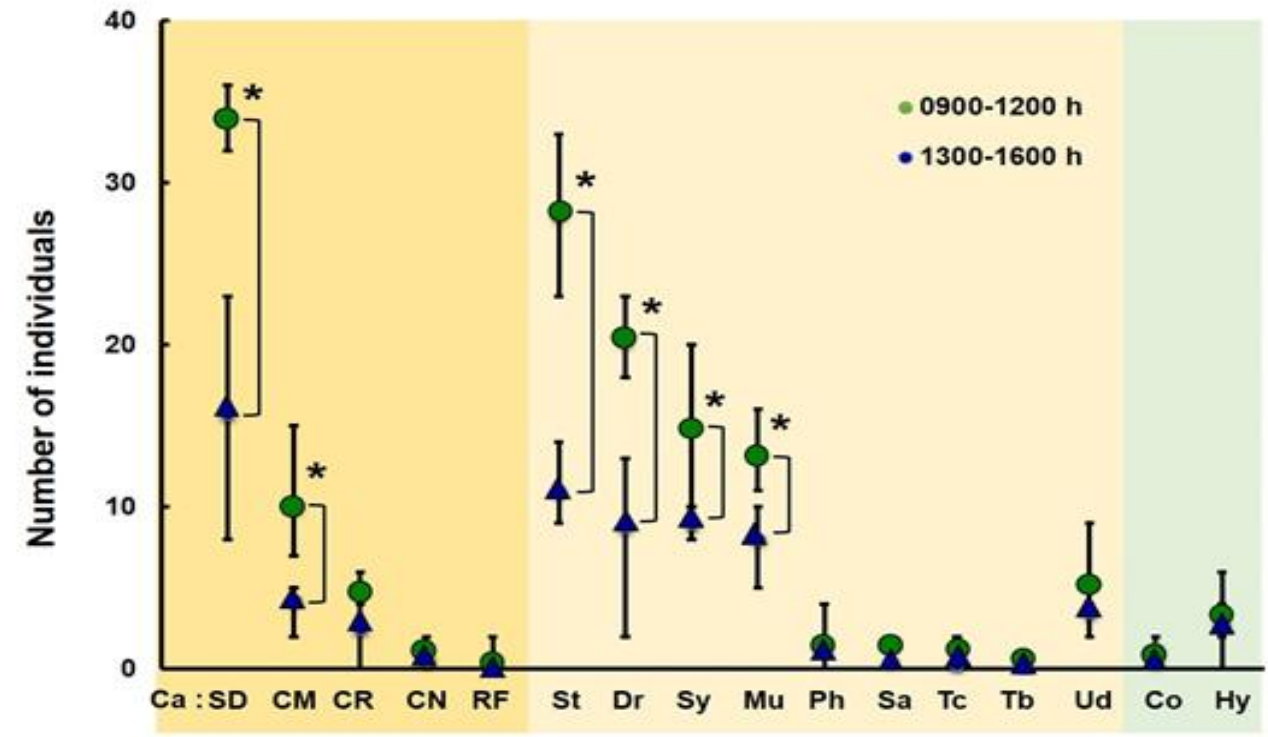

Species of insects

Figure 2. Numbers and visitation times of insects sampled on flowers of Buchanania lanzan at Mahidol University Nakhonsawan Campus, during sampling, 27-28 December 2013 and 13-14 December $2014(n=4)$ (Ca Calliphoridae, SD Stomorhina discolor, CM Chrysomya megacephala, CR Chrysomya rufifacies, CN Chrysomya nigripes, RF Rhyncomya flavibasis, St Stratiomyidae, Dr Drosophilidae, Sy Syrphilidae, Mu Muscidae, Ph Phoridae, Sa Sarcophagidae, Tc Tachinidae, Tb Tabanidae, Ud undetermined Diptera, Co Coleooptera, Hy Hymenoptera); *indicates significant differences in numbers of insects visiting between 0900$1200 h$ and 1300-1600 $h$ (independent T-test, $p<0.05$ ) 
More female flies were caught than males, although this difference was not significant $(p>0.05)$ in most. In muscid flies and sarcophagid flies males predominated over females $(p>0.05)$.

\section{Occurrence of pollens on insect bodies}

Forty-five percent of insects sampled had pollen on their bodies (Table 2). The exceptions were the tiny flies of $D$. melanogaster, $M$. scalaris, and $C$. nigripes, bloodsucking Tabanus sp., and beetles.

Table 2. Percentage of insects with pollen on their bodies at Mahidol University Nakhonsawan Campus during periods of 27-28 December 2013 and 13-14 December 2014

\begin{tabular}{|c|c|c|c|c|c|c|c|}
\hline \multirow{2}{*}{ Order } & \multirow{2}{*}{ Family or Species } & \multirow{2}{*}{$\begin{array}{l}\% \text { of } \\
\text { insects } \\
\text { with } \\
\text { pollens }\end{array}$} & \multicolumn{5}{|c|}{$\%$ of insects bear organs with pollens } \\
\hline & & & Proboscis & Eyes & Thorax & Legs & Abdomen \\
\hline Hymenoptera & Apis mellifera & 75.0 & 0 & 0 & 50.0 & 37.5 & 33.3 \\
\hline \multirow[t]{12}{*}{ Diptera } & Tachinidae & 71.4 & 14.3 & 0 & 57.1 & 57.1 & 42.9 \\
\hline & Graphomya rufitibia & 59.1 & 10.6 & 13.6 & 34.8 & 30.3 & 18.2 \\
\hline & Stomorhina discolor & 58.3 & 6.5 & 0 & 48.7 & 11.1 & 13.1 \\
\hline & Hedriodiscus sp. & 54.3 & 0 & 0 & 31.9 & 24.1 & 15.5 \\
\hline & Syrphidae & 52.6 & 3.2 & 5.1 & 30.8 & 23.1 & 26.3 \\
\hline & Rhyncomya flavibasis & 50.0 & 50.0 & 0 & 50.0 & 0 & 0 \\
\hline & $\begin{array}{l}\text { Chrysomya } \\
\text { megacephala }\end{array}$ & 43.9 & 14.0 & 0 & 12.3 & 33.3 & 24.6 \\
\hline & Musca sorbens & 42.1 & 0 & 0 & 26.3 & 21.1 & 42.1 \\
\hline & Chrysomya rufifacies & 40.0 & 23.3 & 0 & 13.3 & 6.7 & 26.7 \\
\hline & Sarcophagidae & 33.3 & 0 & 0 & 11.1 & 33.3 & 11.1 \\
\hline & Undetermined Diptera & 20.0 & 0 & 0 & 11.4 & 14.3 & 0 \\
\hline & Total & 45.0 & 5.0 & 2.0 & 28.8 & 18.0 & 16.5 \\
\hline
\end{tabular}

The small number of honey bees A. mellifera ( 24 bees) ranked first among the percentage of individuals bearing pollen $(75 \%)$, found on thorax, legs and abdomen. They were followed by tachinid flies (71.4\%) and G. rufitibia (59.1\%), consecutively. $S$. discolor, the most abundant fly sampled in this study, ranked fourth $(58.3 \%$ bore pollen). In flies of these three families pollen was often present on the proboscis in addition to thorax, legs and abdomens. Additionally, pollen grains were attached to the minute hairs located between the facets of compound eyes of both muscid flies, $G$. rufitibia, and syrphid flies. 


\section{Discussion}

The two years' observations revealed that $S$. discolor was the most common blow fly found around opened flowers of B. lanzan. The relationship between this fly species and the flowers of $B$. lanzan has not been previously documented. The length of the pollinator's proboscis is generally related to shape of the flowers they visit (Tangmitcharoen and Owens, 1997). A short proboscis, as found in flies and bees, is usually associated with feeding on already opened flowers (Larson et al., 2001). In addition, different insect pollinators are attracted to flowers of different colors and shades. Flowers with dull colors, such as those of $B$. lanzan, tend to attract fly pollination; while, bright colors mostly attract bees (Shivanna and Tandon, 2014).

In this study, flies preferred to visit flowers in the morning rather than in the afternoon, recalling the findings of Brown and McNeil (2009) for cloudberry Pubus chamaemorus. The peak of diurnal activity differs among different insect species and is usually correlated with the diurnal blooming peak of particular plant hosts. Peak blooming of mango, for example, tends to occur during 0900-1100 h (Huda et al., 2015). The timing of the blooming of $B$. lanzan in relation to $S$. discolor visitation requires further investigation.

Although pollen was found attached to the fly specimens collected in this study, whether any of these fly species is an actual pollinator of this tree is still in question. Banziger et al. (2008) found that despite the fact that blow flies (Calliphora vomitoria (Linnaeus) and Calliphora pattoni Aubertin) entered the lip of the lady slipper orchids Cypridedium yunnanense and $C$. flavum (Orchidaceae), they proved not to be pollinators, even when smeared with pollen. Nonetheless, there are other reports of blow flies as pollinators. For example, females of Lucilia porphyrina, Chrysomya pinguis, Chrysomya chani and Chrysomya villeneuvei were the main pollinators of Rhizanthes zippelii (Rafflesiaceae) in Thailand (Banziger, 1996). Howlett (2012) found that the European blue blow fly Calliphora vicina Robineau-Desvoidy was an effective pollinator of the hybrid carrot (Daucus carota L.) seed crop in New Zealand. In China, several species of blow flies (C. megacephala, Isomyia isomyia, Pierretia sp., Hemipyrellia sp. and C. rufifacies) were the most frequent visitors to flowers of Bridelia stipularis and Cleistanthus sumatranus on tropical Hainan Island (Li et al., 2014). Likewise, females of Lucilia and Chrysomya were major pollinators of Rafflezia pricei in northern Borneo of Malaysia (Beaman et al., 1988). Moreover, C. megacephala blow flies have been reared and used as pollinators of mango in Australia (Anderson et al., 1982) and Taiwan (Hu et al., 1995). In Hong Kong, China, Lau et al. (2009) revealed that C. megacephala provided more effective pollination of Bauhinia sp. (Leguminosae) than honey bees due to its more frequent rate of visitation. Greenhouse experiments would help verify whether $S$. discolor is truly a pollinator of B. lanzan.

In Thailand, the B. lanzan tree is little known although it is found in many parts, especially in the northeastern and central regions (Wongpakam et al., 2007; Sereesongsaeng and Khumchompoo, 2009). It is utilised by local people near Mahidol University Nakhonsawan Campus, who take the young leaves, young shoot tips and flowers of B. lanzan, eating them as a fresh vegetable with Thai dipping paste (chili paste).

Further, although the odor of $B$. lanzan flowers was not strong, unlike carrion flowers; it was remarkable that flies, including medically important blow flies such as $C$. megacephala and C. rufifacies, were attracted to visit. Therefore the odor-causing chemicals of $B$. lanzan flowers should be studied for possible application as a bait to trap those fly species when necessary for pest control. In conclusion, this study sheds 
light on the relationship of $B$. lanzan flowers and the blow fly $S$. discolor under natural conditions in Thailand. These new findings might be useful for further conservation management and economic production of $B$. lanzan, and also for the use of B. lanzan flowers such as the chemicals which they extrude as bait for controlling medicallyimportant fly populations. Such information will help widen our knowledge of the roles of indigenous flies for improving agricultural practice in the future.

Acknowledgements. The staff of Mahidol University, Nakhonsawan Campus, are acknowledged for their help and support during this study. We would like to thank Assoc. Prof. Philip D. Round for editing the manuscript.

\section{REFERENCES}

[1] Anderson, D. L., Sedgley, M., Short, J. R. T., Allwood, A. J. (1982): Insect pollination of mango in northern Australia. - Australian Journal of Agricultural Research 33: 541-548.

[2] Banziger, H. (1996): Pollination of a flowering oddity: Rhizanthes zippelii (Blume) Spach (Rafflesiaceae). - Natural History Bulletin of the Siam Society 44: 113-142.

[3] Banziger, H., Sun, H., Luo, Y. (2008): Pollination of wild lady slipper orchids Cypripedium yunnanense and C. flavum (Orchidaceae) in southwest China. - Botanical Journal of the Linnean Society 156: 51-64.

[4] Beaman, R. S., Decker, P. J., Beaman, J. H. (1988): Pollination of Rafflesia (Rafflesiaceae). - American Journal of Botany 75: 1148-1162.

[5] Brown, A. O., McNeil, J. N. (2009): Pollination ecology of the high lattitude dioecious cloudberry (Rubus chamaemorus; Rosaceae). - American Journal of Botany 96: 10961107.

[6] Bunchu, N. (2012): Blow fly (Diptera: Calliphoridae) in Thailand: distribution, morphological identification and medical importance appraisals. - International Journal of Parasitology Research 4: 57-64.

[7] Bunchu, N., Sukontason, K., Sanit, S., Chidburee, P., Kurahashi, H., Sukontason, K. L. (2012): Occurrence of blow fly species (Diptera: Calliphoridae) in Phitsanulok province, northern Thailand. - Asian Pacific Journal of Tropical Biomedicine 29: 532-543.

[8] Chauhan, P. S., Singh, J., Kavita, A. (2012): Chironjee: a promising tree fruits of dry subtropics. Hort. - HortFlora Research Spectrum 1: 375-379.

[9] Duke, J. A. (2000): Handbook of nuts: herbal reference library. CRC Press 368p.

[10] Greenberg, B. (1973): Flies and disease, Biology and disease transmission. - Princeton University Press.

[11] Kumar, J., Vengaiah, P. C., Srivastav, P. P., Bhowmick, P. K. (2012): Chironji nut (Buchanania lanzan) processing, present practices and scope. - Indian Journal of Traditional Knowledge 11: 202-204.

[11] Kurahashi, H., Bunchu, N. (2011): The blow flies recorded from Thailand, with the description of a new species of Isomyia Walker (Diptera: Calliphoridae). - Japanese Journal of Applied Entomology and Zoology 17: 237-278.

[12] Howlett, B. G. (2012): Hybrid carrot seed crop pollination by the fly Calliphora vicina (Diptera: Calliphoridae). - Journal of Applied Entomology 136: 421-430.

[13] $\mathrm{Hu}, \mathrm{T}$., Len, C. H., Lee, B. S. (1995): The laboratory rearing and radiation effects of gamma ray on the pupae of Chrysomya megacephala (Fabricius). - Chinese Journal of Entomology 15: 103-111.

[14] Huda, A. N., Salmah, M. R., Hassan, A. A., Hamdan, A., Abdul Razak, M. N. (2015): Pollination services of mango flower pollinators. - Journal of Insect Science 113: 1-8.

[15] Larson, B. M. H., Keven, P. G., Inouye, D. W. (2001): Flies and flowers: taxonomic diversity of anthophiles and pollinators. - Canadian Entomologist 133: 439-465. 
[16] Lau, C. P. Y., Saunders, R. M. K., Ramsden, L. (2009): Floral biology, breeding system and population genetic structure of three climbing Bauhinia species (Leguminosae: Caesalpinioideae) in Hong Kong, China. - Journal of Tropical Ecology 25: 147-159.

[17] Li, Y., Luo, S., Zhang, D. (2014): Fly pollination and duodichogamy in Bridelia stipularis and Cleistanthus sumatranus (Phyllanthaceae). - Plant Species Biology 29: E85-E92.

[18] Martin, F. W., Campbell, C. W., Ruberte, R. M. (1988): Perennial edible fruits of the tropics: an inventory. U.S. Department of Agriculture. - Agriculture handbook No. 642. USA Government Printer, Washington, DC 252p.

[19] Patsnaik, A.K., Kodati, D. S., Pareta, K., Patra, K. C., Harwansh, R. K. (2011): Analgesic and anti-inflammatory activities of Buchanania lanzan Spreng. Roots. - Research Journal of Pharmaceutical, Biological and Chemical Sciences 2: 419-425.

[20] Pattnaik, A., Sarkar, R. Sharma, A. K., Yadav, K., Kumar, A., Roy, P., Mazumder, A., Karmakar, S., Sen, T. (2013): Pharmacological studies on Buchanania lanzan spreng.-a focus on wound healing with particular reference to anti-biofilm properties. - Asian Pacific Journal of Tropical Biomedicine 3: 967-974.

[21] Prasad, R., Bhatnagar, P. (1993): Non-wood forest products and the indigenous fringedwellers in Madhya Pradesh. - Journal of Tropical Medicine 9: 188-195.

[22] Rosengarten, F. Jr. (1984): The book of edible nuts. - Walker Publishing Company, Inc. New York 384p.

[23] Sekhar, S., Sampath-Kumara, K. K., Niranjana, S. R., Prakash, H. S. (2015): Attenuation of reactive oxygen/nitrogen species with suppression of inducible nitric oxide synthase expression in RAW 264.7 macrophages by bark extract of Buchanania lanzan. Pharmacognosy Magazine 11: 283-291.

[24] Sereesongsaeng, S., Khumchompoo, S. (2009): Plant diversity plants of Khao Lame Ya Mu Koh Samet national park, Rayong province. - Tropical Plant Research 2: 48-60.

[25] Shivanna, K. R., Tandon, R. (2014): Reproductive Ecology of flowering plants: a manual. - Springer India 170p.

[26] Tangmitcharoen, S., Owens, J. N. (1997): Floral biology, pollination, pistil receptivity, and pollen tube growth of teak (Tectona grandis Linn f.). - Annals of Botany 79: 227241.

[27] Triplehorn, C. A., Johnson, N. F. (2005): Borror and DeLong's introduction to the study of insects, 7th ed. - Thomson Brooks/Cole, Belmont, CA.

[28] Wongpakam, K., Yodsiri, S., Chanaboon, T., Khoomgratok, S., Pramual, P. (2007): Status of Canis aureus in cultural forest in Maha Sarakham province, Thailand. - KKU Research Journal 12: 244-248. 